\title{
Toothbrushing abrasion susceptibility of enamel and dentin bleached with calcium-supplemented hydrogen peroxide gel
}

\author{
A.B. Borges ${ }^{a, *}$, L.F.T.F. Santos ${ }^{a}$, M.G. Augusto ${ }^{a}$, D. Bonfiette ${ }^{a}$, A.T. Hara ${ }^{b}$, C.R.G. Torres ${ }^{a}$ \\ a Department of Restorative Dentistry, Univ. Estadual Paulista, Av. Eng. Francisco José Longo 777, Jardim São Dimas, São José dos Campos, SP, 12245-000, \\ Brazil \\ ${ }^{\mathrm{b}}$ Oral Health Research Institute, Department of Preventive and Community Dentistry, Indiana University School of Dentistry, Indianapolis, IN, USA
}

\section{A R T I C L E I N F O}

\section{Article history:}

Received 15 November 2015

Received in revised form 1 March 2016

Accepted 17 March 2016

\section{Keywords:}

Enamel

Dentin

Tooth bleaching

Hydrogen peroxide

Tooth abrasion

\begin{abstract}
A B S T R A C T
The objective of this study was to evaluate enamel and dentin susceptibility to toothbrushing abrasion, after bleaching with $7.5 \%$ hydrogen peroxide (HP) gel supplemented or not with $0.5 \%$ calcium gluconate (Ca). Toothbrushing was performed immediately and $1 \mathrm{~h}$ after bleaching, with two suspensions (high and low abrasivity). Bovine enamel and dentin specimens were divided into 12 groups ( $n=10)$ according to the bleaching gel (with and without Ca), slurry abrasivity (high or low) and elapsed time after bleaching (immediately and after $1 \mathrm{~h}$ ). As control, a group was not bleached, but abraded. The treatment cycle $(7 \mathrm{~d}$ ) consisted of bleaching $(1 \mathrm{~h})$ and toothbrushing (135 strokes/day) immediatelly or after $1 \mathrm{~h}$ of artificial saliva exposure. Surface roughness and surface loss $(\mu \mathrm{m})$ were measured by profilometry and analysed by three-way ANOVA (5\%). Surface roughness means were significantly influenced by slurry abrasivity $(p<0.0001)$. For enamel loss, significant triple interaction was observed $(p<0.0001)$. HP-bleached groups and immediately brushed with high-abrasive slurry exhibited increased loss $(1.41 \pm 0.14)$ compared to other groups $(\mu \mathrm{m})$. Control and $\mathrm{HP}+\mathrm{Ca}$-bleached groups brushed after $1 \mathrm{~h}$ with low abrasive slurry presented the lowest loss $(0.21 \pm 0.03 / 0.27 \pm 0.02)$. For dentin loss, significant interaction was observed for bleaching and interval factors $(\mathrm{p}<0.001)$. 7.5\%HP-bleached groups and immediately brushed showed significantly higher loss $(8.71 \pm 2.45)$ than the other groups. It was concluded that surface roughness increased when high abrasive was used, independently of bleaching. $7.5 \% \mathrm{HP}$ increased enamel and dentin loss, mainly with high abrasive slurries. Calcium supplementation of bleaching gel reduced surface loss. Additionally, in order to minimize tooth wear susceptibility, it is recommended to delay brushing after bleaching.

Clinical relevance: After bleaching gel application, postponing toothbrushing is recommended, as well as brushing with low abrasive dentifrices. Additionally, supplementation of hydrogen peroxide gel with calcium-based remineralizing agent potentially reduces tooth loss after abrasion.
\end{abstract}

(c) 2016 Elsevier Ltd. All rights reserved.

\section{Introduction}

Hydrogen peroxide has been widely used as a treatment agent for discolored teeth. Due to its low molecular weight and high instability, hydrogen peroxide is able to diffuse through enamel and dentin and decompose, releasing free radicals [1,2]. Its mechanism of action is based on the oxidative destruction of chromophores. This occurs by chemical degradation of molecular

\footnotetext{
* Corresponding author.

E-mail addresses: alessandra@fosjc.unesp.br, alebuhler@gmail.com (A.B. Borges).
}

moieties responsible for absorbing visible eletromagnetic radiation, resulting in the increase of total reflectance of the substrate, and consequently, in its brighter appearance [3].

Although studies have proven the whitening efficacy of bleaching agents, adverse effects on dental tissues are also reported and must be carefully evaluated so that their use can be considered safe $[4,5]$.

Dental bleaching has been previously related to microstructural tooth alterations, such as microhardness reduction [6] and changes in chemical composition of tooth [7]. Morphology defects, such as irregularities, depresssions and porosity formation have also been reported [8]. Although these changes were usually assigned to mineral loss due to the low $\mathrm{pH}$ of bleaching gels [4], degradation of 
the organic matrix by oxidation reaction was reported [9], with the described alterations also observed when near neutral agents were used $[7,8]$. In order to reduce the bleaching gel demineralization potential, the addition of remineralizing agents such as calcium and fluoride in the bleaching agents has been proposed [10-12].

Daily oral hygiene (brushing with regular toothpaste) is usually considered safe and not related to enamel potential harm [13]. However, individuals undergoing bleaching treatment may associate it with high abrasivity whitening toothpastes, potentially increasing its harmful effects on tooth surface [14]. Although abrasivity represents the predominantly mode of action of whitening toothpastes [15], it is known that the degree of dentifrice abrasivity may be related to potential wear, mainly on dentin [16]. Previous studies have reported a higher wear susceptibility of bleached enamel [17] and dentin after brushing [18-20].

Additionally, the effect of toothbrushing abrasion after bleaching on tooth surface roughness has been an issue of concern, since alterations on surface texture can lead to increased susceptibility to staining and bacterial adhesion, and consequently, further discoloration [21,22].

It has been shown that saliva is able to reharden demineralized bleached enamel [11]. Additionally, the supplementation of bleaching agents with remineralizing agents could contribute to reduce any potential harmful effect on bleached tooth [8]. Since bleaching may be related to tooth surface microstructural alterations and its association with toothbrushing can potentially increase surface loss, there is a concern regarding the optimal interval between the removal of the whitening gel and brushing, in order to reduce the possible interaction between the bleaching agent and the abrasive process on dental tissues.

Thus, the aim of this in vitro study was to investigate if the elapsed time between bleaching with $7.5 \%$ hydrogen peroxide (associated or not with calcium) and brushing (with high and low abrasivity slurries) would affect the enamel and dentin roughness and wear. The null hypotheses tested were that: a) $7.5 \%$ hydrogen peroxide, associated or not with calcium would not affect the substrate surface roughness and its susceptibility to abrasive wear; b) the elapsed time between bleaching and brushing would not interfere with roughness and wear, and; c) the slurry abrasivity would not influence roughness and wear.

\section{Materials and methods}

\subsection{Experimental design}

This study followed the complete factorial $3 \times 2 \times 2$ randomized design, with three experimental factors: 1 . bleaching at 3 levels (no bleach, 7.5\% hydrogen peroxide-HP, and HP with the addition of $0.5 \%$ calcium gluconate); 2 . slurry abrasivity at 2 levels according to the RDA values (high and low); and 3. elapsed time between bleaching and abrasion at 2 levels (immediately and $1 \mathrm{~h}$ after bleaching), in a bleaching-abrasion cycling model using bovine enamel and dentin specimens. The specimens were randomly assigned into 12 groups $(n=10)$. The model was conducted for a total of seven consecutive days, and response variables were arithmetic mean surface roughness ( $\mathrm{Ra}$ ) and surface loss (in $\mu \mathrm{m}$ ) measured by contact profilometry.

\subsection{Enamel and dentin specimens preparation}

Freshly extracted and intact bovine incisors were stored until required in $0.1 \%$ thymol solution, refrigerated at $4{ }^{\circ} \mathrm{C}$. Cylindrical enamel and dentin specimens ( $3 \mathrm{~mm}$ diameter) were prepared from the labial surfaces of crowns and roots, respectively, using a custom-made diamond trephine mill. The specimens were then embedded in auto-polymerizable acrylic resin using cylindrical silicone molds ( $6 \mathrm{~mm}$ diameter, $3 \mathrm{~mm}$ depth), with the labial surface exposed for treatments, as previously described [23].

Embedded specimens were ground flat and polished with water-cooled sequential aluminum oxide abrasive papers (1200, 2400 and 4000 grit FEPA P; Struers, Ballerup, Denmark) in a polishing device (DP 10, Panambra, Sao Paulo, SP, Brazil). After each grindpaper, specimens were sonicated in deionized water for $5 \mathrm{~min}$. The prepared specimens were examined in stereomicroscope (20X-Carl Zeiss, Stemi 2000, Tokyo, Japan) to verify the absence of cracks or other surface defects and then stored in ultrapure water to prevent dehydration.

The baseline profiles of the enamel and dentin surfaces were measured using a contact profilometer (MarSurf GD 25, Mahr, Göttingen, Germany). In order to maintain the reference surfaces for lesion-depth determination, and allow the exact superimposition of the baseline and post-treatment profiles, two parallel grooves were marked as guides on the resin at the sides of the embeded tooth structure. The specimens were positioned into a custom-made specimen holder attached to the profilometer, which allows the exact repositioning of the sample after the treatments. The diamond stylus moved from the first reference (resin) to the enamel or dentin area and then over to the other reference area ( $4.2 \mathrm{~mm}$ long). Three profile measurements were performed for each specimen at intervals of $0.25 \mathrm{~mm}$.

For baseline superficial roughness analysis, the mean surface roughness values ( $\mathrm{Ra}$ ) were determined with a cut-off value of $0.8 \mathrm{~mm}$, a transverse length of $0.8 \mathrm{~mm}$, and a stylus speed of $0.1 \mathrm{~mm} / \mathrm{s}$, in the previously described profiles.

\subsection{Bleaching and abrasive procedures}

The specimens were randomly allocated into 12 groups $(n=10)$. The first group division was according to the bleaching gel: NB- no bleach; HP- 7.5\% hydrogen peroxide gel ( $\mathrm{pH}$ 5.62); $\mathrm{HP}+\mathrm{Ca}-7.5 \% \mathrm{HP}$ gel with the addition of $0.5 \%$ calcium gluconate $(\mathrm{pH} 5.60)$. The experimental gels were modified by the manufacturer (FGM, Joinville, SC, Brazil), by adding or not the calcium compound in a 7.5\% HP-based bleaching gel.

A $2 \mathrm{~mm}$ thick layer of the bleaching gel was daily applied to the specimens' surface and remained for $1 \mathrm{~h}$. After this period, the gel was removed with a suction tip and the surface rinsed with ultrapure water for $20 \mathrm{~s}$. In the non-bleached groups, the specimens remained in ultrapure water during the period corresponding to bleaching procedure.

After the described procedures, the specimes of each described group were divided according to the elapsed time after bleaching into two subgroups: immediatelly and one hour after bleaching for performing toothbrushing. The specimens of the group $1 \mathrm{~h}$ were

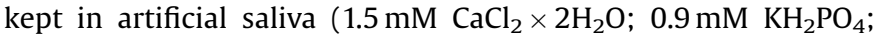
$130 \mathrm{mM} \mathrm{KCl} ; 20 \mathrm{mM}$ of HEPES; pH adjusted to 7.0 with $1 \mathrm{M} \mathrm{KOH}$ solution) [24].

The specimens were finally divided into two subgroups according to the slurry abrasivity: $\mathrm{H}$ - high and L- low. The abrasive challenge was performed using an automatic toothbrushing machine (SEM-2T, Odeme Dental Research, Luzerna, SC, Brazil), which imparted reciprocating motion to standard medium bristle toothbrush stiffness (Sanifill Ultraprofissional, Sao Paulo, Brazil). The brushes were angled $15^{\circ}$ in relation to the specimen surface to minimize grooves formation. During brushing, the right and left sides of the specimens, corresponding to acrylic resin with the reference groves, were protected with a stainless steel mask (0.1$\mathrm{mm}$ thick), with an opened window of $2-\mathrm{mm}$ wide, leaving an exposed area in the center of each specimen, preventing the abrasion of reference areas for the profilometric analysis. 
Table 1

Mean (SD) values of roughness (Ra initial, Ra final and Ra alteration- final - initial) for enamel and dentin, according to the tested groups.

\begin{tabular}{|c|c|c|c|c|c|c|c|c|}
\hline Treatments & & & Enamel & & & Dentin & & \\
\hline Bleaching & Interval & Abrasive & Ra initial & Ra final & Ra alter. & Ra initial & Ra final & Ra alter. \\
\hline \multirow[t]{7}{*}{ No bleaching } & \multirow[t]{3}{*}{ Immed. } & High & $\begin{array}{l}0.025 \\
(0.006)\end{array}$ & $\begin{array}{l}0.088 \\
(0.042)\end{array}$ & $\begin{array}{l}0.063 \\
(0.044)\end{array}$ & $\begin{array}{l}0.044 \\
(0.019)\end{array}$ & $\begin{array}{l}0.188 \\
(0.047)\end{array}$ & $\begin{array}{l}0.144 \\
(0.062)\end{array}$ \\
\hline & & \multirow[t]{2}{*}{ Low } & 0.024 & 0.043 & 0.020 & 0.044 & 0.090 & 0.046 \\
\hline & & & $(0.005)$ & $(0.018)$ & $(0.001)$ & $(0.011)$ & $(0.017)$ & $(0.018)$ \\
\hline & \multirow[t]{4}{*}{ After $1 \mathrm{~h}$} & \multirow[t]{2}{*}{ High } & 0.022 & 0.078 & 0.055 & 0.042 & 0.192 & 0.150 \\
\hline & & & $(0.005)$ & $(0.034)$ & $(0.034)$ & $(0.016)$ & $(0.035)$ & $(0.038)$ \\
\hline & & \multirow[t]{2}{*}{ Low } & 0.022 & 0.040 & 0.018 & 0.049 & 0.126 & 0.076 \\
\hline & & & $(0.007)$ & $(0.032)$ & $(0.030)$ & $(0.017)$ & $(0.029)$ & $(0.028)$ \\
\hline \multirow[t]{8}{*}{$7.5 \% \mathrm{HP}$} & \multirow[t]{4}{*}{ Immed. } & \multirow[t]{2}{*}{ High } & 0.021 & 0.090 & 0.068 & 0.051 & 0.174 & 0.123 \\
\hline & & & $(0.007)$ & $(0.035)$ & $(0.041)$ & $(0.019)$ & $(0.055)$ & $(0.047)$ \\
\hline & & \multirow[t]{2}{*}{ Low } & 0.021 & 0.050 & 0.028 & 0.045 & 0.100 & 0.055 \\
\hline & & & $(0.006)$ & $(0.025)$ & $(0.025)$ & $(0.015)$ & $(0.031)$ & $(0.040)$ \\
\hline & \multirow[t]{4}{*}{ After $1 \mathrm{~h}$} & \multirow[t]{2}{*}{ High } & 0.019 & 0.075 & 0.055 & 0.046 & 0.151 & 0.104 \\
\hline & & & $(0.006)$ & $(0.035)$ & $(0.037)$ & $(0.016)$ & $(0.033)$ & $(0.034)$ \\
\hline & & \multirow[t]{2}{*}{ Low } & 0.024 & 0.048 & 0.023 & $0.046(0.015)$ & 0.114 & 0.068 \\
\hline & & & $(0.006)$ & $(0.017)$ & $(0.016)$ & & $(0.011)$ & $(0.017)$ \\
\hline \multirow[t]{8}{*}{$7.5 \% \mathrm{HP}+\mathrm{Ca}$} & \multirow[t]{4}{*}{ Immed. } & \multirow[t]{2}{*}{ High } & 0.024 & 0.088 & 0.064 & $0.047(0.015)$ & 0.169 & 0.122 \\
\hline & & & $(0.004)$ & $(0.038)$ & $(0.037)$ & & $(0.047)$ & $(0.045)$ \\
\hline & & \multirow[t]{2}{*}{ Low } & 0.029 & 0.043 & 0.014 & 0.049 & 0.115 & 0.066 \\
\hline & & & $(0.008)$ & $(0.030)$ & $(0.027)$ & $(0.017)$ & $(0.014)$ & $(0.019)$ \\
\hline & \multirow[t]{4}{*}{ After $1 \mathrm{~h}$} & \multirow[t]{2}{*}{ High } & 0.023 & 0.070 & 0.046 & 0.050 & 0.183 & 0.133 \\
\hline & & & $(0.005)$ & $(0.027)$ & $(0.029)$ & $(0.014)$ & $(0.045)$ & $(0.051)$ \\
\hline & & \multirow[t]{2}{*}{ Low } & 0.026 & 0.041 & 0.015 & $0.054(0.013)$ & 0.106 & 0.051 \\
\hline & & & $(0.007)$ & $(0.017)$ & $(0.021)$ & & $(0.019)$ & $(0.027)$ \\
\hline
\end{tabular}

Daily, 135 brushing strokes under a vertical load of $200 \mathrm{~g}$ with abrasive slurry were administered, simulating 45 strokes each time, three times a day [25]. The slurries were prepared by mixing the silica abrasives Zeodent 113 (low abrasive, with RDA [standarderror] 86.92 [1.54] and REA [standard-error] 4.45 [0.46], J.M. Huber, Etowah, TN, USA) or Zeodent 103 (high abrasive, RDA [standarderror] 204.07 [5.21] and REA [standard-error] 5.49 [0.43], J.M. Huber) with a $5 \%$ carboxymethilcellulose solution in glycerol. An abrasive concentration of $10 \%$ was used [25]. The bleaching/abrasion procedures were repeated for 7 days.

\subsection{Surface loss and roughness analysis}

After the end of treatment, the final profiles of the surfaces were measured using the contact profilometer following the same parameters previously described. Final surface roughness was determined with the same especifications described before. The surface loss was calculated after superimposing the baseline and post-treatment profiles, using the previously described grooves as guides. The depth of the treated area for each specimen was calculated based on the subtraction of the two profiles, using a dedicated software (MarSurf-XCR 20 4.50-07 SP3, 2011). The background noise, used for calculation of the detection limit of the equipment, was recorded by measuring the vertical displacement of the stationary stylus for $20 \mathrm{~s}$, according to the methodology described by Attin et al. [26]. This determined $0.132 \mu \mathrm{m}$ as the lower limit of measurement. Therefore, readings below this value are considered "below detection limit".

\subsection{Statistical analysis}

The difference between final and initial enamel and dentin values of arithmetic mean surface roughness (Ra) and surface loss $(\mu \mathrm{m})$ from the surface of the enamel and dentin at the end of the experiment served as evaluation parameters. ANOVA three-way and post-hoc Tukey tests were used for both data. The level of significance was $5 \%$.

\section{Results}

The mean values of initial and final surface roughness for both enamel and dentin substrates, as well as the roughness change are shown in Table 1.

Three-way ANOVA was applied both on enamel and dentin Ra alteration data (final-initial) and showed differences only for the abrasive factor $(p<0.001)$. The factors bleaching treatment $(p=0.41$ enamel $/ p=0.15$ dentin $)$ and interval post-bleaching $(p=0.18$ enamel $/ p=0.50$ dentin) did not present significant differences, as well as the three-factors interaction $(\mathrm{p}=0.88$ enamel $/ \mathrm{p}=0.20$ dentin). Brushing with the high abrasive slurry resulted in enamel and dentin Ra means significantly higher than with the low abrasive one.

The enamel surface loss analysis was also performed using three-way ANOVA, which showed significant differences for all factors $(\mathrm{p}<0.001)$, and for the triple interaction $(\mathrm{p}<0.001)$. Tukey's test results are presented in Fig. 1 and showed that bleaching with $7.5 \% \mathrm{HP}$ resulted in higher enamel lost compared to $7.5 \% \mathrm{HP}+\mathrm{Ca}$ and control groups, for both immediate and after $1 \mathrm{~h}$ interval. The means obtained with high abrasive were higher than the same groups brushed with low abrasive slurries. The immersion of specimens in artificial saliva for $1 \mathrm{~h}$ after bleaching resulted in lower enamel loss compared to the immediate groups.

For dentin, there were significant differences for the three distinct factors $(\mathrm{p}<0.001)$ and for interaction between bleaching and interval factors $(\mathrm{p}<0.001)$, shown in Fig. 1 . The results of Tukey test showed that the groups bleached with $7.5 \%$ HP and immediately brushed showed significantly higher loss than the other groups tested (asterisks in Fig. 2).

\section{Discussion}

As the bleaching procedure is an esthetic treatment, all consequences that could affect the outcome are relevant. Surface loss potentially caused by brushing can cause damage to enamel and dentin during the years, weakening the tooth structure. Additionally, the effect of the bleaching treatment over the surface 


\section{Enamel}

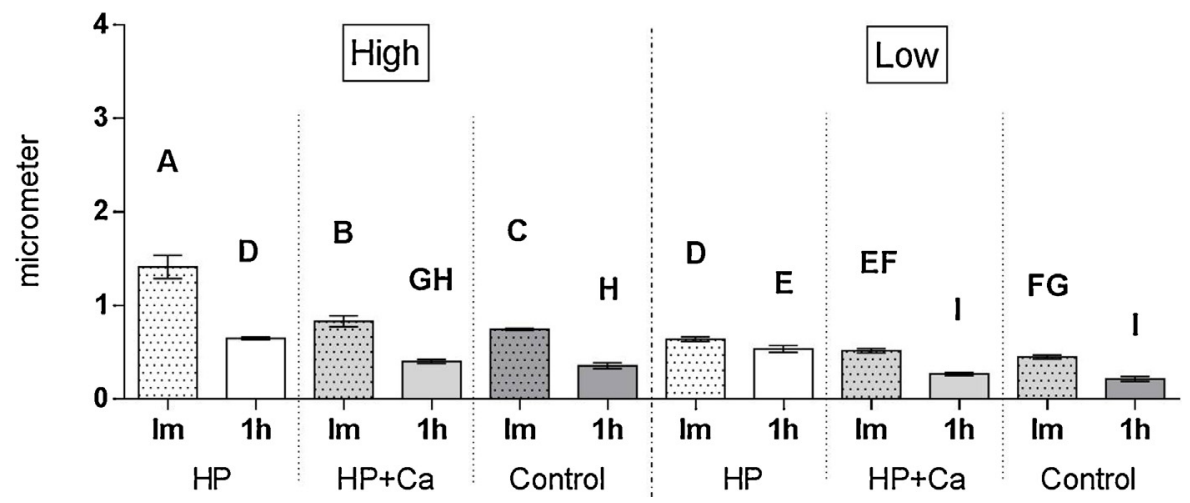

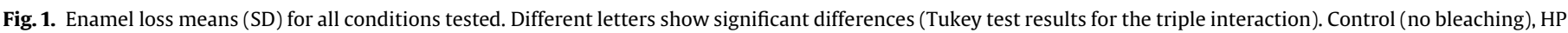
(bleaching with $7.5 \%$ hydrogen peroxide), $\mathrm{HP}+\mathrm{Ca}$ (bleached with $7.5 \%$ hydrogen peroxide and $0.5 \%$ calcium gluconate), Immediate (Im), after $1 \mathrm{~h}$ ( $1 \mathrm{~h}$ ).

roughness can produce a more immediate negative esthetic effect, such as the formation of a scratchy surface, with increased susceptibility to extrinsic stains deposition [21]. Besides, roughness values as low as $0.25 \mu \mathrm{m}$ can be perceived by the tongue, potentially causing discomfort to the patient [27]. Another consequence would be the biofilm deposition over rough surfaces [22]. A threshold surface roughness for bacterial retention of $0.2 \mu \mathrm{m}$ has been reported [28].

In this in vitro study, the overall enamel and dentin surface roughness after abrasion associated or not with bleaching significantly increased compared to baseline polished specimens data. Additionally, the roughness alteration caused by brushing with high abrasive slurry was higher when a low abrasive dentifrice simulation was tested. Nevertheless, the bleaching procedures did not exacerbate the brushing effects on enamel and dentin surface roughness. Thus, only the second null hypothesis tested regarding abrasivity was rejected.

The deleterious effect of bleaching gels on tooth structures is an issue of concern, since it is known that hydrogen peroxide agents are able to penetrate enamel structure through the boundaries between nanocrystals and decompose, releasing free radicals [1]. These radicals are unspecific and act not only on cromogens, but can cause the breakage of the polypeptide chain by means of destruction of aminoacids present in tooth organic matrix $[9,29]$.
As a consequence, several authors reported alterations on both enamel and dentin morphology and chemical composition [7,8]. Since the organic content participates on enamel integrity, these changes may result in mineral content changes [9].

Nevertheless, the effect of peroxide-based gels on enamel and dentin surface roughness is controversial, as some authors reported increased roughness after bleaching [30] and others did not observe significant differences [31,32]. Comparison among the studies is difficult, since bleaching agents, concentrations and protocols are different. It is important to note that the remineralization action of saliva is able to minimize the previously reported deleterious effect of bleaching procedures on tooth structure $[4,5,11]$.

When bleaching was associated with toothbrushing abrasion, increased enamel roughness has been reported [33-35]. Nevertheless, we found that, regardless the bleaching treatment, the roughness alteration was determined by the toothbrushing procedure, modulated by the slurry abrasivity. Similar results were also obtained previously for bleached/abraded enamel [36]. Toothpaste abrasivity is mainly based on a radiotracer method, which provides relative abrasivity of dentin and enamel (RDA and REA), comparing them to a reference abrasive [37]. It has to be highlighted that although we classified as low and high abrasive, both slurries abrasivity were within the recommended range of ISO

\section{Dentin}

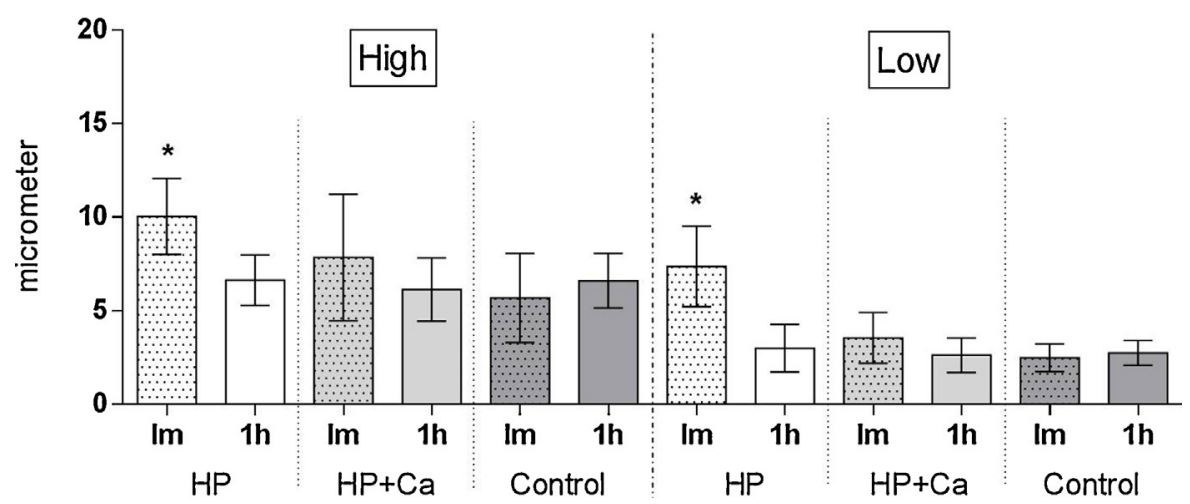

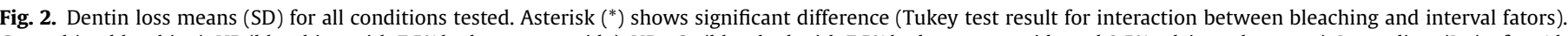

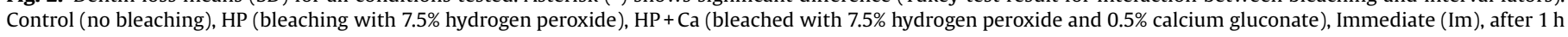
(1 h). 
(bellow RDA 250) [38]. On the other hand, while the toothpastes usually contain fluoride, in this study the slurries were not fluoridated, as this could represent a confounding factor for the calcium-supplemented bleaching agent, potentially interfering with the remineralization action. Additionaly, it was previously demonstrated that fluoridation of dentifrice did not alter its potential to affect enamel roughness [33].

Since abrasivity was the determining factor for surface roughness, postponing the brushing procedure $1 \mathrm{~h}$ after bleaching did not excert a protective effect for minimizing the surface roughness effects, contrarily as reported previously [39]. The irregularities caused by brushing probably were coarser than the supposed repairing action of saliva over the surface morphologic irregularities of bleached enamel and dentin.

Although the alterations in surface roughness can influence esthetic results, it is probably less clinically relevant than the potential wear process that can be related to toothbrushing associated to hydrogen peroxide use. In this study, it was overall observed that bleaching with $7.5 \%$ hydrogen peroxide associated with abrasive challenge for seven days resulted in significantly higher enamel and dentin loss than the non-bleached control group and the $7.5 \%+$ Ca bleached group. Therefore, the first null hypothesis was rejected for both substrates.

Although the effect of bleaching agents did not significantly affect surface roughness, probably because the slurry abrasivity effect overcomes the demineralization action of bleaching agents, it increased surface loss. It is speculated that the potentially demineralized surface may have been more easily removed by toothbrushing abrasion. Increased abrasive wear has been associated to bleached enamel [17] and especially to bleached dentin $[19,20]$. Similarly, the abrasion resistance of dental hard tissues was shown to be reduced in demineralized surfaces [38] and bleached enamel abrasive susceptibility has been related to peroxide concentration [17]. During bleaching procedures, enamel can lose calcium and phosphate ions to the oral environment [7,30]. Although demineralization potential of bleaching agents is mainly related to its $\mathrm{pH}[4,6]$, it was already demonstrated that its oxidative effect is also related to subsequent mineral loss [9].

The addition of remineralizing agents in a bleaching gel can minimize its demineralization potential and possibly promote ions incorporation in the demineralized enamel [10,12]. Although calcium and phosphate ions needed for remineralization process are naturally present in saliva, the presence of calcium in bleaching gel aims to act as a supplementary source of these ions in the tooth surface, mantaining its saturation during bleaching $[10,12]$. Calcium gluconate was added in order to minimize the demineralization potential of the bleaching gel and eventually contribute to the desensitizing effect. The salt is soluble at the conditions needed for the bleaching gel production and is easily found in adequate chemical purity [40]. According to the manufacturer (FGM), the concentration of $0.5 \%$ was determined during the product development process, in order to maintain its adequate viscosity and stability. The protective effect of calcium supplementation in bleaching gel was also demonstrated for bleached enamel further exposed to acidic solutions [23,41]. Similarly, different calcium compounds have also been added to acidic beverages in order to reduce enamel wear when subjected to erosion [42].

The remineralization potential of saliva over demineralized dental hard tissues could eventually reduce the abrasive wear, although this is a very controversial issue and a definite protective time (if really relevant) has not yet been established. Waiting periods of at least $1 \mathrm{~h}$ after demineralization by erosion has shown to slightly reduce enamel abrasion $[43,44]$, and therefore used in this study. Our results showed that bleached substrates abraded $1 \mathrm{~h}$ post-bleaching generally exhibited reduced loss compared to immediately brushed. It has to be pointed out that, when present, the demineralization pattern promoted by bleaching product are supposed to be milder, since it has a different origin compared to acid-exposed eroded substrate. The artificial saliva may have restored the potentially surface-damaged bleached structure, reducing substrate abrasion susceptibility. On the other hand, the absence of proteins in artificial saliva may have favored salivaremineralizing properties, limiting the comparison with in situ studies [45].

In relation to slurry abrasivity, increased enamel and dentin loss was observed when higher abrasive slurry was used. The in vitro correlation of tooth wear with dentifrice abrasivity has been previously demonstrated [46]. Nevertheless, only dentin-increased abrasion has been related with toothpaste abrasivity, but associated with erosion [47] or with bleaching/erosion [18]. It has to be notet that enamel loss observed was negligible compared to dentin loss, and may not be clinically worrying. Although bleaching agents should not be applied over exposed dentin, occasionally it can reach the partially exposed root dentin when gingival retraction is present.

The in vitro nature of the present study should be taken into account, since it does not consider the presence of human saliva and acquired pellicle formation. It was demonstrated that the calcium, phosphate and fluoride content of human saliva may be responsable for mantaining mineral content and inhibit enamel demineralization during bleaching treatment [4] or promote remineralization due to a supersaturation of mineral components $[5,11]$. Aditionally, it must be highlighted that the profilometry methodology demands polished specimens. The removal of native surface may favor demineralization process and exacerbate test results [48]. Thus, extrapolation of the results to clinical reality must be carefully performed.

\section{Conclusion}

Considering the limitations of this in vitro study, it can be concluded that surface roughness was only influenced by slurry abrasivity. 7.5\% hydrogen peroxide bleaching may increase enamel and dentin susceptibility to abrasion, mainly with high abrasive slurries. Supplementation of bleaching gel with calcium and delaying brushing for one hour after bleaching reduced surface loss.

\section{Acknowledgments}

This study was supported by Sao Paulo State Research Foundation (FAPESP-10/50637-7). The authors thank FGM Produtos Odontologicos for manufacturing the experimental bleaching agents and Ivan Balducci for helping with statistical analysis.

\section{References}

[1] C.R. Torres, C.S. Souza, A.B. Borges, M.F. Huhtala, T.M. Caneppele, Influence of concentration and activation on hydrogen peroxide diffusion through dental tissues in vitro, Sci. World J. 2013 (2013) 193241.

[2] C.R. Torres, E. Crastechini, F.A. Feitosa, C.R. Pucci, A.B. Borges, Influence of pH on the effectiveness of hydrogen peroxide whitening, Oper. Dent. 39 (6) (2014) E261-8.

[3] J.J. Dannacher, Catalytic bleach: most valuable applications for smart oxidation chemistry, J. Mol. Catal. A Chem. 251 (2006) 159-176.

[4] Y. Sa, D. Chen, Y. Liu, W. Wen, M. Xu, T. Jiang, et al., Effects of two in-office bleaching agents with different $\mathrm{pH}$ values on enamel surface structure and color: an in situ vs. in vitro study, J. Dent. 40 (Suppl. 1) (2012) e26-e34.

[5] M. Zeczkowski, L.M. Tenuta, G.M. Ambrosano, F.H. Aguiar, D.A. Lima, Effect of different storage conditions on the physical properties of bleached enamel: an in vitro vs in situ study, J. Dent. 43 (9) (2015) 1154-1161.

[6] A.B. Borges, K.C. Yui, T.C. D’Avila, C.L. Takahashi, C.R. Torres, A.L. Borges, Influence of remineralizing gels on bleached enamel microhardness in different time intervals, Oper. Dent. 35 (2) (2010) 180-186.

[7] F.Y. Cakir, Y. Korkmaz, E. Firat, S.S. Oztas, S. Gurgan, Chemical analysis of enamel and dentin following the application of three different at-home bleaching systems, Oper. Dent. 36 (5) (2011) 529-536.

[8] I. Quintela Souza de Moraes, L. Nunes de Brito Silva, I.C. Celerino de Moraes Porto, C.F. de Lima Neto, N. Barbosa Dos Santos, L. Silveira de Mendonça 
Fragoso, Effect of in-office bleaching with 35\% hydrogen peroxide with and without addition of calcium on the enamel surface, Microsc. Res. Tech. 78 (11) (2015) 975-981.

[9] T. Jiang, X. Ma, Y. Wang, H. Tong, X. Shen, Y. Hu, et al., Investigation of the effects of $30 \%$ hydrogen peroxide on human tooth enamel by Raman scattering and laser-induced fluorescence, J. Biomed. Opt. 13 (1) (2008) 014019.

[10] A.B. Borges, L.Y. Samezima, L.P. Fonseca, K.C. Yui, A.L. Borges, C.R. Torres, Influence of potentially remineralizing agents on bleached enamel microhardness, Oper. Dent. 34 (5) (2009) 593-597.

[11] A.B. Borges, C.A. Guimaräes, E. Bresciani, C.J. Ramos, A.L. Borges, C. Rocha Gomes Torres, Effect of incorporation of remineralizing agents into bleaching gels on the microhardness of bovine enamel in situ, J. Contemp. Dent. Pract. 15 (2) (2014) 195-201.

[12] V. Cavalli, L.K. Rodrigues, A.F. Paes-Leme, L.E. Soares, A.A. Martin, S.B. Berger et al., Effects of the addition of fluoride and calcium to low-concentrated carbamide peroxide agents on the enamel surface and subsurface, Photomed. Laser Surg. 29 (5) (2011) 319-325.

[13] M. Addy, M.L. Hunter, Can tooth brushing damage your health? Effects on oral and dental tissues, Int. Dent. J. 53 (Suppl. 3) (2003) 177-186.

[14] C.F. Melo, F.B. Manfroi, A.M. Spohr, Microhardness and roughness of enamel bleached with $10 \%$ carbamide peroxide and brushed with different toothpastes: an in situ study, J. Int. Oral Health 6 (4) (2014) 18-24.

[15] S. Alshara, F. Lippert, G.J. Eckert, A.T. Hara, Effectiveness and mode of action of whitening dentifrices on enamel extrinsic stains, Clin. Oral Invest. 18 (2) (2014) $563-569$.

[16] E. Macdonald, A. North, B. Maggio, F. Sufi, S. Mason, C. Moore, et al., Clinical study investigating abrasive effects of three toothpastes and water in an in situ model, J. Dent. 38 (6) (2010) 509-516.

[17] A. Wiegand, Y.A. Otto, T. Attin, In vitro evaluation of toothbrushing abrasion of differently bleached bovine enamel, Am. J. Dent. 17 (6) (2004) 412-416.

[18] K. Engle, A.T. Hara, B. Matis, G.J. Eckert, D.T. Zero, Erosion and abrasion of enamel and dentin associated with at-home bleaching: an in vitro study, J. Am. Dent. Assoc. 141 (5) (2010) 546-551.

[19] J.J. Faraoni-Romano, C.P. Turssi, M.C. Serra, Effect of a 10\% carbamide peroxide on wear resistance of enamel and dentine: in situ study, J. Dent. 37 (4) (2009) 273-278.

[20] J.P. Lima, M.A. Melo, V.F. Passos, C.L. Braga, L.K. Rodrigues, S.L. Santiago, Dentin erosion by whitening mouthwash associated to toothbrushing abrasion: a focus variation 3D scanning microscopy study, Microsc. Res. Tech. 76 (9)(2013) 904-908.

[21] V. Cavalli, C.A. Arrais, M. Giannini, G.M. Ambrosano, High-concentrated carbamide peroxide bleaching agents effects on enamel surface, J. Oral Rehabil. 31 (2) (2004) 155-159.

[22] C. Wang, Y. Zhao, S. Zheng, J. Xue, J. Zhou, Y. Tang, et al., Effect of enamel morphology on nanoscale adhesion forces of streptococcal bacteria: an AFM study, Scanning 37 (5) (2015) 313-321.

[23] L.F. Santos, C.R. Torres, T.M. Caneppele, A.C. Magalhães, A.B. Borges, Effect of home-bleaching gels modified by calcium and/or fluoride and the application of nano-hydroxyapatite paste on in vitro enamel erosion susceptibility, Acta Odontol. Scand. 74 (2) (2016) 121-126.

[24] J.M. ten Cate, R.A. Exterkate, M.J. Buijs, The relative efficacy of fluoride toothpastes assessed with pH cycling, Caries Res. 40 (2) (2006) 136-141.

[25] T. Scaramucci, A.B. Borges, F. Lippert, N.E. Frank, A.T. Hara, Sodium fluoride effect on erosion-abrasion under hyposalivatory simulating conditions, Arch. Oral Biol. 58 (10) (2013) 1457-1463.

[26] T. Attin, K. Becker, M. Roos, R. Attin, F. Paque, Impact of storage conditions on profilometry of eroded dental hard tissue, Clin. Oral Invest. 13 (4) (2009) 473478.

[27] C.S. Jones, R.W. Billington, G.J. Pearson, The in vivo perception of roughness of restorations, Br. Dent. J. 196 (1) (2004) 42-45.
[28] C.M. Bollen, P. Lambrechts, M. Quirynen, Comparison of surface roughness of oral hard materials to the threshold surface roughness for bacterial plaque retention: a review of the literature, Dent. Mater. 13 (4) (1997) 258-269.

[29] K. Kawamoto, Y. Tsujimoto, Effects of the hydroxyl radical and hydrogen peroxide on tooth bleaching, J. Endod. 30 (1) (2004) 45-50.

[30] D.G. Soares, A.P. Ribeiro, N.T. Sacono, A.D. Loguércio, J. Hebling, C.A. Costa, Mineral loss and morphological changes in dental enamel induced by a $16 \%$ carbamide peroxide bleaching gel, Braz. Dent. J. 24 (5) (2013) 517-521.

[31] F.K. Cobankara, N. Unlü, H.C. Altinöz, O. Füsun, Effect of home bleaching agents on the roughness and surface morphology of human enamel and dentine, Int. Dent. J. 54 (4) (2004) 211-218.

[32] R.T. Basting, A.L. Rodrigues, M.C. Serra, Micromorphology and surface roughness of sound and demineralized enamel and dentin bleached with a $10 \%$ carbamide peroxide bleaching agent, Am. J. Dent. 20 (2) (2007) 97-102.

[33] C.C. Worschech, J.A. Rodrigues, L.R. Martins, G.M. Ambrosano, Brushing effect of abrasive dentifrices during at-home bleaching with $10 \%$ carbamide peroxide on enamel surface roughness, J. Contemp. Dent. Pract. 7 (1) (2006) 25-34.

[34] P. Özkan, G. Kansu, S.T. Özak, S. Kurtulmus-Yilmaz, P. Kansu, Effect of bleaching agents and whitening dentifrices on the surface roughness of human teeth enamel, Acta Odontol. Scand. 71 (3-4) (2013) 488-497.

[35] S.P. Hilgenberg, S.C. Pinto, P.V. Farago, F.A. Santos, D.S. Wambier, Physicalchemical characteristics of whitening toothpaste and evaluation of its effects on enamel roughness, Braz. Oral Res. 25 (4) (2011) 288-294.

[36] R. Pachaly, R.T. Pozzobon, Analysis of surface roughness of human enamel exposed to bleaching agent and submitted to brushing, Acta Odontol. Latinoam. 25 (1) (2012) 59-66.

[37] A. Wiegand, M. Kuhn, B. Sener, M. Roos, T. Attin, Abrasion of eroded dentin caused by toothpaste slurries of different abrasivity and toothbrushes of different filament diameter, J. Dent. 37 (6) (2009) 480-484.

[38] A. Wiegand, N. Schlueter, The role of oral hygiene: does toothbrushing harm? Monogr. Oral Sci. 25 (2014) 215-219.

[39] E.J. Navimipour, N. Mohammadi, S. Mostafazadeh, M. Ghojazadeh, P.A. Oskoee, Effect of delaying toothbrushing during bleaching on enamel surface roughness: an in vitro study, Oper. Dent. 38 (2) (2013) 218-225.

[40] The United States Pharmacopeial Convention. Rockville M. 2015 [acessed 18/ 01/2016]; Available from: http://www.pharmacopeia.cn/v29240/ usp29nf24s0_m11660.html.

[41] A.B. Borges, C.R. Torres, P.A. de Souza, T.M. Caneppele, L.F. Santos, A.C. Magalhães, Bleaching gels containing calcium and fluoride: effect on enamel erosion susceptibility, Int. J. Dent. 2012 (2012) 347848.

[42] T. Scaramucci, A.T. Hara, D.T. Zero, S.S. Ferreira, I.V. Aoki, M.A. Sobral, In vitro evaluation of the erosive potential of orange juice modified by food additives in enamel and dentine, J. Dent. 39 (12) (2011) 841-848.

[43] T. Attin, S. Knofel, W. Buchalla, R. Tutuncu, In situ evaluation of different remineralization periods to decrease brushing abrasion of demineralized enamel, Caries Res. 35 (3) (2001) 216-222.

[44] T. Jaeggi, A. Lussi, Toothbrush abrasion of erosively altered enamel after intraoral exposure to saliva: an in situ study, Caries Res. 33 (6) (1999) 455-461.

[45] A. Lussi, J. Lussi, T.S. Carvalho, B. Cvikl, Toothbrushing after an erosive attack: will waiting avoid tooth wear? Eur. J. Oral Sci. 122 (5) (2014) 353-359.

[46] C.J. Philpotts, E. Weader, A. Joiner, The measurement in vitro of enamel and dentine wear by toothpastes of different abrasivity, Int. Dent. J. 55 (3 Suppl. 1) (2005) 183-187.

[47] C.P. Turssi, J.J. Faraoni, A.L. Rodrigues Jr., M.C. Serra, An in situ investigation into the abrasion of eroded dental hard tissues by a whitening dentifrice, Caries Res. 38 (5) (2004) 473-477.

[48] A. Young, L.M. Tenuta, Initial erosion models, Caries Res. 45 (Suppl 1) (2011) 33-42. 